\title{
FACTORS AFFECTING PHYSICIAN'S ADHERENCE TO GENERIC DRUG PRESCRIBING PRACTICE IN PRIVATE HEALTH FACILITIES, MEKELLE CITY, NORTHEASTERN ETHIOPIA
}

\author{
Birhanu Demeke Workneh ${ }^{1}$, Terefe Teshome Kassa ${ }^{2}$, Fantaye Teka Dinkashe ${ }^{3 *}$, Tsegay \\ Aregawi $^{2}$, Tigist Assefa Bayou ${ }^{2}$, Meles Tekie Gidey ${ }^{2}$, Yared Belete Belay ${ }^{2}$ \\ ${ }^{1}$ Department of Pharmacy, College of Health Sciences, Wollo University, Dessie, Ethiopia \\ ${ }^{2}$ Department of Pharmacy, College of Health Sciences, Mekelle University, Mekelle, Ethiopia \\ ${ }^{3}$ Forecasting and Capacity Building Directorate, The Federal Democratic Republic of Ethiopia Pharmaceutical Fund and Supply Agency, Addis \\ Ababa, Ethiopia
}

\section{ABSTRACT}

Introduction: Generic medicines are produced by multiple manufacturers hence, are usually cheaper than innovator brands and therefore save costs on medicines. Many physicians oppose brand substitution, believing generic medicines to be inferior to their originator counterparts. Physicians' belief about generic medicines and factors affecting generic prescribing in Ethiopia are poorly investigated.

Objective: To assess the physicians' belief about generic medicines and to identify factors affecting generic medicines prescribing in private health facilities, Mekelle, Northern Ethiopia.

Materials and Methods: An institution based cross-sectional study was conducted enrolling all physicians working in private health facilities. The data were collected from January 2016 to March 2016. Data were collected using self-administered structured questionnaires measuring generic medicines belief of physicians using a Likert scale of 1-5. Data were then entered into SPSS version 20 for analysis.

Results: Of the fifty-six physicians approached in this study, 50 (89.2\% response rate) questionnaires were included in the analysis. Nearly three-fourth $(72 \%)$ of the physicians claimed that they always prescribe generic medicines. More than half (55.3) of the respondents beliefs generic medicines have different active ingredients than a brand innovator. Almost equal percentage (52\% and $54 \%$ ) of the Physicians disagreed with brand medicines were safer than generic medicines and prescribing generic due to the complicated health problem of the patient respectively. Around two third $(67.5 \%)$ of physicians reported that quality profile of medicine was a major reason for prescribing generic medicines. Moreover, availability of medicines in pharmacies and low cost of medicines were the main reasons for prescribing generic medicines with $58.1 \%$ and $52.4 \%$ respectively.

Conclusion: The majority of physicians do not have a positive perception of generic medicines and a significant portion of the physician's belief brand medicines safer and effective than generic counterparts. The availability of medicines in pharmacies, low cost of medicines and purchasing power of the patients are major factors affecting generic medicines prescribing.

Keywords: Generic medicines, belief, private health facilities, physicians

\section{Article Info}

Received 31 Jan 2017; Review Completed 23 Feb 2017; Accepted 24 Feb 2017, Available online 15 March 2017

\section{Cite this article as:}

Workneh BD, Kassa TT, Dinkashe FT, Aregawi T, Bayou TA, Gidey MT, Belay YB,Factors affecting physician's adherence to generic drug prescribing practice in private health facilities, mekelle city, northeastern Ethiopia, Journal of Drug Delivery and Therapeutics. 2017; 7(2):44-49. DOI: http://dx.doi.org/10.22270/jddt.v7i2.1394

\section{*Address for Correspondence}

Fantaye Teka Dinkashe, Forecasting and Capacity Building Directorate, The Federal Democratic Republic of Ethiopia Pharmaceutical Fund and Supply Agency, Addis Ababa, Ethiopia. Email: fantaphar@gmail.com 


\section{INTRODUCTION}

A generic medicine is a product that can be interchangeable with the innovator product, which does not need a license from the innovator, and manufactured after the expiration of the patent or other exclusivity rights. ${ }^{1-3}$ In order to be approved, a generic medicine should be bioequivalent to the originator product, and must be the same in terms of strength, safety and quality ${ }^{1,4,5}$ while generic medicines could differ from their equivalent branded medicine in their color, size, shape and excipient ingredients, they must be able to demonstrate bioequivalence to the originator medicine in terms of bioavailability and the rate of absorption. ${ }^{2,6}$

Generic medicines are produced by multiple manufacturers hence, are usually cheaper than innovator brands and therefore save costs on medicines. ${ }^{1,4,5}$ Study conducted in 17 developing countries reported an average of $9-89 \%$ expenditure could be saved by each country in private sector purchases by switching from originator brands to lowest-priced generics. ${ }^{5}$ Generic formulations offer the same therapeutic effect as branded medicines at a much more lowest price. ${ }^{7}$ Because of this, generic drugs have been dramatically popular as a method to reduce pressure on drug budgets, and they now make up a significantly increasing percentage of consumed drugs. ${ }^{8}$

Many physicians oppose brand substitution, believing generic medicines to be inferior to their originator counterparts. $^{9}$ In the UK, there was strong opposition when planned to introduce generic replacement into UK primary care. ${ }^{10}$ However, Public and private third-party payers and health care regulatory authorities increasingly encourage or obligate the use of generics through measures such as generic prescribing and generic substitution. ${ }^{11-15}$

The use of generics has increased significantly in the last two decades. Although generic prescribing by physicians, is advocated in most countries, the extent to which this is put to practice differs significantly as do monitoring and evaluation by health insurance companies ${ }^{16,17}$ and generic substitution laws. ${ }^{18}$ Generic drug prescription policies differ from country to country globally. The practice of generic medicines prescribing and substitution in developing countries has been controversial among healthcare professionals, principally due to issues on quality, safety and efficacy. ${ }^{19}$ The use of generics is therefore often promoted in the public and private sectors to save medicine expenditure, and enhance product availability and client access. $^{20}$ In Ethiopia, clinical practice guidelines enforce a prescription should be using generic names of the medicine(s). ${ }^{21}$

Private health care at present, accounts for over two thirds of total healthcare expenditure ${ }^{22,23}$ and over $70 \%$ of the entire expenditure on pharmaceuticals. $^{24}$ Currently, there is limited prescribing of generics specifically in the private sector, for instance. a study revealed over $90 \%$ of patients in the private sector typically demand originators and prices of generics vary from 0.2 to 7.02 times that of international market reference prices among a basket of products. ${ }^{23,25}$
The prescribing behavior of physicians is considered to be crucial for generic utilization as they determine whether their patients require branded drugs or generic drugs. ${ }^{26}$ A generic medicine may not always be suitable for the patient. ${ }^{27}$ Several factors may significantly influence the physicians prescribing behavior such as the trust and the quality image of the manufacturer company. ${ }^{28}$ Physicians' prescribing practice can also be influenced by pharmaceutical manufacturers through a variety of incentives such as high-end education programs or even some cash payment for prescriptions. ${ }^{29}$ In addition, free samples and gifts can also be provided ${ }^{30}$ so that a targeted drug's name stays topmost in subconscious mind of the prescribers. ${ }^{31}$ Therefore, these incentives may indirectly influence the patients, by encouraging them to use costly originator products instead of in the same way effective, lower-cost generics. ${ }^{32}$ Globally, physicians are much more responsive to arguments about a drug's effectiveness than about its price. ${ }^{33}$ Physicians with better education, better training on rational drug use and better possession of medicine understanding prescribe a lower percentage of generic drugs. ${ }^{34}$

Physicians' belief about generic medicines and factors affecting generic prescribing in Ethiopia are poorly investigated. Therefore, this study narrows the knowledge gap and the findings of the current study assist policy makers regarding generic prescribing in the future. The main objective of the study was to assess physicians' belief about generic medicines and to identify factors affecting generic medicines prescribing in private health facilities, Mekelle, Ethiopia.

\section{METHODS AND MATERIALS}

The study was conducted in Mekelle city is main city of Tigray regional state, Ethiopia. Mekelle city is found at $783 \mathrm{Km}$ Northeast of Addis Ababa, which is the capital of Ethiopia. Mekelle city has one comprehensive specialized referral hospital, three general hospitals, three private hospitals, sixty-three private clinics and nine health centers. This institution-based cross sectional study was conducted from January 13, 2016 to March 20, 2016.

All physicians (56) working in private health facilities were considered as the study population. Physicians inclusion criteria were experience of 6 months or greater in Mekelle city, whereas the exclusion criteria were unwilling to participate in the study and unable to fill out the questionnaire.

Data were collected using self-administered questionnaire. The questionnaire had three different sections. The first part of the questions addresses socio demographic characteristics of respondents which followed by questions about generic medicines belief and finally questions about the reason for prescribing generic medicines were included. One day training was given to data collectors and supervisors on how to collect data from the respondents. Pretest was done on $5 \%$ of the questionnaires at Quiha hospital, which were not the part of the study area and the result was not 


\section{Workneh et al}

included. Daily on the spot-checking of filled questionnaires for errors or any incompleteness was done by holding daily discussions among data collectors.

The collected data were entered, cleaned and analyzed using SPSS version 20 statistical software. Frequencies and percentages were done for categorical variables. The normality of the population distribution was checked with histogram for continuous variables, for nonnormally distributed population the measure of central tendency (median) and a measure of dispersion (interquartile range) was reported.

Ethical clearance was obtained from Ethical Review Committee of College of Health Sciences, Mekelle University. Written permission was also obtained from the Tigray Regional Health Bureau, Mekelle city Health office and informed consent was obtained from individual respondents. Participants' information which gets from the questionnaires was kept confidential. Participants were also informed that participation was voluntary and they had right to refuse answering to any of the questions.

\section{RESULTS}

Of the 56 physicians working in a private health facility, 50 of them were voluntary to participate in this study which made a response rate of $89.2 \%$. Forty six (92\%) of physicians were males with Median age of 32 years and with an Inter quartile range (IQR) of 12. Among all respondents $28(56 \%)$ and $22(44 \%)$ were married and were specialists respectively. Nearly half $(48 \%)$ of the study participants have had an experience of less than or equal to five years (Table 1).

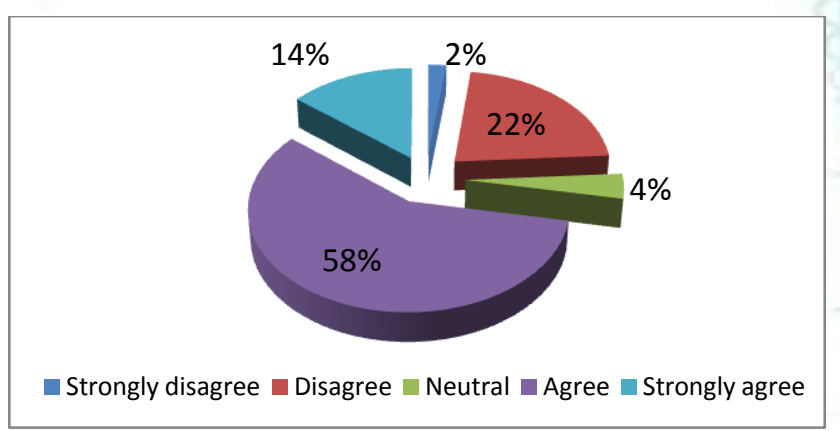

Figure 1: Physician $(\mathrm{N}=50)$ response to always prescribe generic medicines in Private Health Facilities, Mekelle, Ethiopia, 2016
Journal of Drug Delivery \& Therapeutics. 2017; 7(2):44-49

Table 1: Socio-demographic characteristics of the Physicians in Private Health Facilities, Mekelle, Ethiopia, $2016(\mathrm{~N}=50)$.

\begin{tabular}{|l|l|l|}
\hline $\begin{array}{l}\text { Socio-demographic } \\
\text { characteristics }\end{array}$ & Frequency & Percentage \\
\hline Age (years) & & \\
\hline$\leq 30$ & 22 & 44.0 \\
\hline $31-40$ & 17 & 34.0 \\
\hline$\geq 41$ & 11 & 22.0 \\
\hline Sex & & \\
\hline Male & 46 & 92.0 \\
\hline Female & 4 & 8.0 \\
\hline Marital status & & \\
\hline Married & 28 & 56.0 \\
\hline Single & 22 & 44.0 \\
\hline Educational status & & \\
\hline First degree (GP) & 19 & 38.0 \\
\hline Specialist & 22 & 44.0 \\
\hline Resident & 9 & 18.0 \\
\hline Experience (years) & & \\
\hline$\leq 5$ & 24 & 48.0 \\
\hline $6-15$ & 18 & 36.0 \\
\hline$\geq 16$ & 8 & 16.0 \\
\hline
\end{tabular}

Approximately three fourth $(72 \%)$ of the physicians reported that they always prescribe generic medicines while $28 \%$ of respondents were neutral or disagree to prescribe generics (Figure 1).

Above half $(55.3 \%)$ of the study participants reported that they believe that generic medicines have different active ingredients to that of brand medicines and almost equal percentage (52\% and $54 \%$ ) of the respondents disagreed with brand medicines were safer than generic medicines and prescribing generic due to the complicated health problem of the patient respectively. Twenty six (52\%) of the physicians believed that locally produced drugs were equally effective as the brand products. In addition, nearly three fourth $(72 \%)$ of the study participants strongly disagreed or disagreed with the concept of brand medicines were cost effective than generic counterparts (Table 2).

Table 2: Physicians belief about generic medicines in Private Health Facilities, Mekelle, Ethiopia, $2016(\mathrm{~N}=50)$.

\begin{tabular}{|l|l|l|l|l|l|l|}
\hline S. & Statement & N $(\%)$ & \multicolumn{3}{|l|}{} \\
\cline { 3 - 6 } & & $\begin{array}{l}\text { Strongly } \\
\text { disagree }\end{array}$ & Disagree & Neutral & Agree & $\begin{array}{l}\text { Strongly } \\
\text { agree }\end{array}$ \\
\hline 1 & $\begin{array}{l}\text { Generic medicines have different active ingredients } \\
\text { than brand medicines }\end{array}$ & $4(10.5)$ & $9(23.7)$ & $4(10.5)$ & $15(39.5)$ & $6(15.8)$ \\
\hline 2 & Brand medicines are safer than generic medicines & $8(16)$ & $18(36)$ & $10(20)$ & $13(26)$ & $1(2)$ \\
\hline 3 & $\begin{array}{l}\text { Locally produced medicines are equally effective as } \\
\text { original brand medicines }\end{array}$ & $3(6)$ & $14(28)$ & $6(12)$ & $22(44)$ & $5(10)$ \\
\hline 4 & $\begin{array}{l}\text { Generic medicines are similar with brand counterpart } \\
\text { in all aspects }\end{array}$ & $16(45.7)$ & $12(34.5)$ & $3(8.6)$ & $2(5.7)$ & $2(5.7)$ \\
\hline 5 & $\begin{array}{l}\text { Brand medicines are cost effective than generic } \\
\text { medicines }\end{array}$ & $10(20)$ & $26(52)$ & $6(12)$ & $6(12)$ & $2(4)$ \\
\hline 6 & $\begin{array}{l}\text { Brand medicines are prescribed for complicated } \\
\text { conditions }\end{array}$ & $9(18)$ & $18(36)$ & $11(22)$ & $12(24)$ & $0(0)$ \\
\hline
\end{tabular}


Around two third $(67.5 \%)$ of physicians claimed that quality profile of medicine were major reason for prescribing generic medicines while the majority of respondents declared that they disagreed with the statement "I prescribe generic medicines due to peer norms". Approximately equal (58.1 and 52.4) percent of respondents agreed with availability of medicines in pharmacies and low cost of medicines were among the main reasons for prescribing generic medicines (Table 3).

Table 3: The main reasons of physicians for prescribing generic medicines in Private Health Facilities, Mekelle, Ethiopia, $2016(\mathbf{N}=50)$.

\begin{tabular}{|l|l|l|l|l|l|l|}
\hline S.N. & Reason for prescribing generic drug & \multicolumn{2}{l|}{ N $(\%)$} \\
\cline { 3 - 7 } & & $\begin{array}{l}\text { Strongly } \\
\text { disagree }\end{array}$ & Disagree & Neutral & Agree & $\begin{array}{l}\text { Strongly } \\
\text { agree }\end{array}$ \\
\hline 1 & Due to peer norms & $7(20)$ & $18(51.4)$ & $3(8.6)$ & $4(11.4)$ & $3(8.6)$ \\
\hline 2 & Quality profile of the medicine & $1(2.5)$ & $3(7.5)$ & $9(22.5)$ & $22(55)$ & $5(12.5)$ \\
\hline 3 & $\begin{array}{l}\text { Availability of the medicines in } \\
\text { pharmacies }\end{array}$ & $2(4.5)$ & $7(15.9)$ & $5(11.4)$ & $24(54.5)$ & $6(13.6)$ \\
\hline 4 & Low cost of the medicine & $9(21.4)$ & $8(19)$ & $3(7.1)$ & $12(28.6)$ & $10(23.8)$ \\
\hline
\end{tabular}

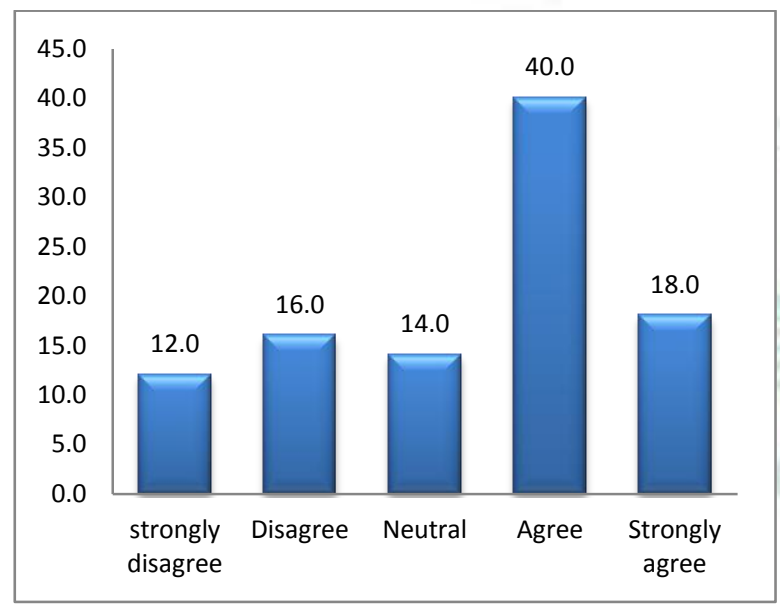

Figure 2: Response of physicians towards influence of medical representatives on prescribing brand medicines in Private Health Facilities, Mekelle, Ethiopia, 2016 (N=50).
More than half $(52 \%)$ of the study participants believed that they were prescribed brand medicines on the basis of purchasing power of the patients. Above half 27 $(58 \%)$ of the physicians strongly agreed or agreed that they prescribe brand medicines due to the influence of medical representative (Figure 2).

Chi-square test was done to see the association between the dependent and various independent variables by considering p-value of 5\% significant level. As table 3 indicated the proportion of male physicians who prescribe generic drugs was $34(73.9 \%)$ and the proportion of female physicians who prescribe generic drugs was $2(50.0 \%)$ with p-value of 0.307.The proportion of general practitioners, specialists and other professionals to prescribe generic medicines was $16(44.4 \%), 15(41.7 \%)$ and $5(13.9 \%)$ respectively with a p-value of 0.25 (Table 4).

Table 4: Association between the dependent and various independent variables among physicians in Mekelle city 2016 $(\mathrm{N}=50)$.

\begin{tabular}{|c|c|c|c|c|}
\hline \multirow[t]{2}{*}{ Variables } & \multirow[t]{2}{*}{ Categories } & \multicolumn{2}{|c|}{ Generic drug prescription } & \multirow[t]{2}{*}{ P-Value } \\
\hline & & $\begin{array}{l}\text { Yes } \\
\text { N }(\%)\end{array}$ & $\begin{array}{l}\text { No } \\
\text { N }(\%) \\
\end{array}$ & \\
\hline \multirow[t]{2}{*}{ Sex } & Male & $34(73.9)$ & $12(26.1)$ & \multirow[t]{2}{*}{0.307} \\
\hline & Female & $2(50.0)$ & $2(50.0)$ & \\
\hline \multirow[t]{2}{*}{ Marital Status } & Married & $20(71.4)$ & $8(28.6)$ & \multirow[t]{2}{*}{0.919} \\
\hline & Single & $16(72.7)$ & 627.3( & \\
\hline \multirow[t]{3}{*}{ Religion } & Orthodox & $31(70.5)$ & $13(29.5)$ & \multirow[t]{3}{*}{0.352} \\
\hline & Muslim & $1(50.0)$ & $1(50.0)$ & \\
\hline & Protestant & $4(100.0)$ & $0(0)$ & \\
\hline \multirow[t]{3}{*}{ Educational status } & First degree (GP) & $16(44.4)$ & $3(15.8)$ & \multirow[t]{3}{*}{0.250} \\
\hline & Specialist & $15(41.7)$ & $7(31.8)$ & \\
\hline & Other specify (Resident or HO) & $5(13.9)$ & $4(44.4)$ & \\
\hline
\end{tabular}

\section{DISCUSSIONS}

From the current study $72 \%$ of physicians claimed that they always prescribe generic medicine, which is slightly lower than the study finding in Ghana which revealed $79.2 \%$ of medicines prescribed by generic name, the reason for the difference of the two finding may be a study conducted in Ghana only consider antibiotic but the current study couldn't specify medicine group, the other study conducted in Jordan depicted that from the physician's $62.8 \%$ (often) and $14.6 \%$ (very 


\section{Workneh et al}

often) prescribe generic medicine instead of an originator brand which is comparable with our findings. ${ }^{35,36}$ In the current study, $28 \%$ of physician claimed that brand medicines are safer than generic medicine which is comparable with one systematic review that showed a greater proportion of doctors $(836 / 2928,28.54 \%$, 95\%) believed that generic medicines are equally safer with brand medicine. In this review significantly higher proportion of physicians held the view that generic drugs were less effective than their brand name equivalents $(1450 / 5056 ; 28.68 \%)$ but in the current study, $34 \%$ of physician's couldn't accept locally produced medicines as equally effective as original brand medicines. Their view on the quality profile of the medicine might be the reason for such response. $^{8}$ One study done in Nigeria depicted that 105 $(68.2 \%)$ respondents would prefer to recommend generic medicines over branded ones, while 49 (31.8\%) respondents preferred to recommend branded medicines over generics in their practice. ${ }^{37}$ The current study reported $11.4 \%$ of the participants claimed that generic medicines are similar to a brand counterpart in all aspects but $80.2 \%$ couldn't accept this similarity. A study conducted in Pakistan Punjab showed 53\% physicians consider the Socio-economic status of the patient to prescribe medicine, a similar study reported $35 \%$ of a physician at Khyber Pakhtonkhwe(KPK). ${ }^{38}$ In the current study, $52 \%$ of the study participants believed that they were prescribed brand medicines on the basis of purchasing power of the patients which is comparable with that of Punjab and higher than KPK's finding. Another study in Malaysia revealed cost of drugs $31(88.6 \%)$ and socio-economics status of the patients $16(45.7 \%)$ are factors that influences clinicians prescribing intent; this is lower than that of the current study likewise, the study was done in Jordan showed $58.5 \%$ of physician's believed that the cost is important, $10.6 \%$ believed that the cost is highly important, whereas $30.9 \%$ of the physicians believed that the cost is not important at all but the result of Jordan study also a bit higher than from that of our study. ${ }^{35,39}$ The difference in study participants, sample size and medicine specification could be the probable reason for the difference in findings. From the current study above half $27(58 \%)$ of the physicians strongly agreed or agreed that they prescribe brand medicines due to the medical representative influence which is higher than the study conducted previously in similar study area which reports $40(48.2 \%)$ of the physicians believed that their prescribing behaviors were influenced by visits of MRs and reports from Kentucky physicians indicated that they used information supplied by pharmaceutical representatives in their clinical practice $5.4 \%$ daily, $31.3 \%$ weekly, $47.7 \%$ monthly, and $14.4 \%$ yearly. ${ }^{31,40} \mathrm{~A}$ systematic review that scrutinizes this area figure out all randomized control trials $(100 \%)$ showed nonsignificant differences between generic and brand-name drugs. The aggregate effect size was 0.01 (95\% CI $0.05 ; 0.08$ ) for soft outcomes; -0.06 (95 \% CI -0.71 ; 0.59 ) for hard outcomes, both indicating no difference between generic and brand-name drugs. Much the same results were observed for each drug class and in each
Journal of Drug Delivery \& Therapeutics. 2017; 7(2):44-49

stratified meta-analysis. ${ }^{1}$ But, in our study, only $11.4 \%$ of participants believed generic medicines are similar to a brand counterpart in all aspects. In the current study $67.5 \%$ of the participants prescribe generic medicine due to their quality profile of medicine which is higher than from the findings that reported from Greek, that indicate half of the physicians characterize the quality of generics in terms of efficacy, safety and effectiveness as 'very high' or 'high' when compared with the respective original products. ${ }^{41}$

This study implies those socio-demographic factors of physicians like sex, marital status, religion and educational status has had no significant association with generic prescribing behavior, on contrary to our findings the report of Greek revealed Physician's age and opinion on generics' efficacy and effectiveness were identified as important determinants of their prescribing decisions and reports from university of Maryland showed differences in both the propensity of physicians to prescribe generics and in physicians' experiences may arise because of differences in the institutional features of where physicians practice (urban versus rural, group versus single practice, etc.) or because of the demographic characteristics of physicians (age, place of medical education, etc.) or characteristics of their patients. $^{41,42}$

A possible limitation of this study could be the study population used for this study was very small. Second, this survey was conducted only among Physicians working in private health facilities in the Mekelle city. Therefore, the generalizability to physicians practicing in other facilities is somewhat limited. Third, the study is a cross-sectional type and thus it did not investigate cause and effect relationship. Nevertheless, this survey can serve as a preliminary study and is helpful in understanding the belief of Physicians on issues pertaining to generic medicines use in Ethiopia.

\section{CONCLUSION}

In conclusion the majority of physicians do not have a positive perception of generic medicines and a significant portion of the physician's belief brand medicines safer and effective than generic counterparts. The main factors affecting the prescription of generic medicines by physicians have been identified in this study: the availability of medicines in pharmacies, low cost of medicines and the basis of purchasing power of the patients.

Acknowledgments: The authors acknowledge the support of the Department of Pharmacy, College of Health Sciences, Mekelle University, in facilitating the data collection process. We are thankful for Physicians who participated in the study and private health facilities in Mekelle for their willingness in the data collection process.

Disclosure: No fund was gained in the conduct of this study. Authors have declared that no competing interests exist. 


\section{REFERENCES}

1. Manzoli L. Flacco ME. Boccia S. et al. Generic versus brandname drugs used in cardiovascular diseases. Eur J Epidemiol. 2016; 31:351-368.

2. World Health Organization: Trade, foreign policy, diplomacy and health: generic drugs.

http://www.who.int/trade/glossary/story034/en/ (accessed January 8, 2013).

3. Auta A, Bala ET, Shalkur D. Generic medicine substitution: a cross-sectional survey of the perception of pharmacists in northcentral, Nigeria. Medical Principles and Practice. 2013; 23(1):538.

4. World Health Organization. Globalization (2004), Trade and Health, Available from: http://www.who.int/trade/glossary/story 034/en/index.html.

5. Homedes N, Ugalde A. Multisource drug policies in Latin America: survey of 10 countries. Bulletin of the World Health Organization. 2005; 83(1): 64-70.

6. Chong CP, Hassali MA, Bahari MB, etal.Evaluating community pharmacists' perceptions of future generic substitution policy implementation: a national survey from Malaysia. Health Policy. 2010; 94: 68-75.

7. Cameron A, Mantel-Teeuwisse AK, Leufkens HGM, etal.Switching from originator brand medicines to generic equivalents in selected developing countries: how much could be saved? Value Health. 2012; 15: 664-673.

8. Colgan S, Faasse K, Martin LR, Stephens MH, Grey A, Petrie KJ. Perceptions of generic medication in the general population, doctors and pharmacists: a systematic review. BMJ open. 2015 5(12):e008915.

9. Shrank WH, Liberman JN, Fischer MA, Girdish C, Brennan TA, Choudhry NK. Physician perceptions about generic drugs. Annals of Pharmacotherapy. 2011; 45(1):31-8.

10. Ferner R, Lenney W, Marriott J, et al. Controversy over generic substitution. BMJ.2010; 340:c1341-3.

11. Johnston A, Asmar R, Dahlöf B, et al. Generic and therapeutic substitution: a viewpoint on achieving best practice in Europe. British journal of clinical pharmacology. 2011; 72(5):727-30.

12. Jacobzone S. Pharmaceutical Policies in OECD Countries: Reconciling Social and Industrial Goals. Paris: OECD; 2000.

13. Garattini L, Tediosi F. A comparative analysis of generics markets in five European countries. Health Policy. 2000; 51(3):149-162.

14. DanzonPM, Chao LW. Cross-national price differences for pharmaceuticals: how large, and why? J Health Econ. 2000; 19(2):159-195.

15. Danzon PM, Chao LW. Does regulation drive out competition in pharmaceutical markets? J Law Econ. 2000; 43:311-357.

16. King DR, Kanavos P: Encouraging the use of generic medicines.implications for transition economies. Croatian Medical. 2002; 43(4): 462-9.

17. Haas JS, Phillips KA, Gerstenberger EP, SegerAC.Potential savings from substituting generic drugs for brand-name drugs: medical expenditure panel survey, 1997-2000. Annals of Internal Medicine. 2005; 142(11):891-7.

18. Iosifescu A, Halm EA, McGinn T, Siu AL, Federman AD. Beliefs about generic drugs among elderly adults in hospital-based primary care practices. Patient education and counseling. 2008; 73(2):377-83

19. Awaisu A, Kheir N, Ibrahim MI, El-Hajj M, Hazi H, Khudair N, Barazi R. Knowledge, attitudes, and practices of community pharmacists on generic medicines in Qatar. International journal of clinical pharmacy. 2014; 36(2):394-404.

20. Cameron A, Mantel-Teeuwisse AK, Leufkens HG, Laing RO. Switching from originator brand medicines to generic equivalents in selected developing countries: how much could be saved? Value in Health. 2012 Aug 31; 15(5):664-73.

21. Food, Medicine and Healthcare Administration and Control Authority of Ethiopia: Standard Treatment Guidelines for General Hospital; Addis Ababa Ethiopia. $3^{\text {rd }}$ ed. Addis Ababa; 2014, Available at: http://apps.who.int/medicinedocs/documents/s21694en/s21694en. pdf
22. World Health Organization. Pakistan - Medicine prices, availability, affordability and pricecomponents. Availablefrom:http://www.haiweb.org/medicineprices/ surveys /200407PK/sdocs/Pakistan-summary-report-web.pdf. Accessed June 20, 2016.

23. Jamshed SQ, Ibrahim MI, Hassali MA, et al. Perception and attitude of general practitioners regarding generic medicines in Karachi, Pakistan: A questionnaire based study. Southern med review. 2012; 5(1):22-30.

24. Profile c. pharmaceutical country profile. 201. Available from: http://www.who.int/medicines/areas/coordination/pakistan.pdf. Accessed June 24, 2016.

25. Zaidi S, Bigdeli M, Aleem N, Rashidian A. Access to essential medicines in Pakistan: policy and health systems research concerns. PloS one. 2013 May 22; 8(5):e63515.

26. Abratt R, Lanteigne J. Factors influencing general practitioners in the prescription of homeopathic medicines. South African Journal of Business Management. 2000; 31(3).

27. Bakthavathsalam G. Generic drugs: cost effective alternate to branded drugs. Health Admin. 2006;19(1):16-9.

28. Moss G, Schuiling I. A brand logic for pharma?: A possible strategy based on FMCG experience. Journal of Medical Marketing: Device, Diagnostic and Pharmaceutical Marketing. 2004; 4(1):55-62.

29. Seiter A. A practical approach to pharmaceutical policy. World Bank Publications; 2010.

30. El-Dahiyat F, Kayyali R, Bidgood P. Physicians' perception of generic and electronic prescribing: A descriptive study from Jordan. Journal of pharmaceutical policy and practice. 2014; $7(1): 1$.

31. Workneh BD, Gebrehiwot MG, Bayo TA, et al. Influence of Medical Representatives on Prescribing Practices in Mekelle, Northern Ethiopia. PloS one. 2016; 11(6):e0156795.

32. Roberts MJ. Pharmaceutical reform: a guide to improving performance and equity. World Bank Publications; 2011.

33. Scherer FM. Pricing, profits and technological progress in the pharmaceutical industry. J Econ Perspect.1993; 7(3): 97-115.

34. Wang H, Li N, Zhu H, Xu S, Lu H, Feng Z. Prescription pattern and its influencing factors in Chinese county hospitals: a retrospective cross-sectional study. PLoS One. 2013; 8(5):e63225.

35. El-Dahiyat F, Kayyali R, Bidgood P. Physicians' perception of generic and electronic prescribing: A descriptive study from Jordan. Journal of pharmaceutical policy and practice. 2014; 7(1):1.

36. Ahiabu MA, Tersbøl BP, Biritwum R, Bygbjerg IC, Magnussen P. A retrospective audit of antibiotic prescriptions in primary healthcare facilities in Eastern Region, Ghana. Health policy and planning. 2015 Jun 4:czv048

37. Auta A, Bala ET, Shalkur D. Generic medicine substitution: a cross-sectional survey of the perception of pharmacists in northcentral, Nigeria. Medical Principles and Practice. 2013; 23(1):53-

38. Riaz H, Godman B, Hussain S, Malik F, Mahmood S, Shami A, Bashir S. Prescribing of bisphosphonates and antibiotics in Pakistan: challenges and opportunities for the future. Journal of Pharmaceutical Health Services Research. 2015; 6(2):111-21.

39. Akter SF, Rani MF, Rahman JA, Nordin MS, Satwi S, Awang MB. Antimicrobial use and factors influencing prescribing in medical wards of a tertiary care hospital in Malaysia. Int $J$ Sci Environ Technol. 2012; 1(4):274-84

40. Caudill TS, Johnson MS, Rich EC, McKinney WP. Physicians, pharmaceutical sales representatives, and the cost of prescribing. Archives of Family Medicine. 1996; 5(4):201-6.

41. Tsiantou V, Zavras D, Kousoulakou H, Geitona M, Kyriopoulos J. Generic medicines: Greek physicians' perceptions and prescribing practices. Journal of clinical pharmacy and therapeutics. 2009; 34(5):547-54.

42. Hellerstein JK. The importance of the physician in the generic versus trade-name prescription decision. The Rand journal of economics. 1998:108-36. 